\title{
Neck Pain, CTCAE 5.0
}

National Cancer Institute

\section{Source}

National Cancer Institute. Neck Pain, CT CAE 5.0. NCI Thesaurus. Code C146766.

A disorder characterized by a sensation of marked discomfort in the neck area. 